\title{
Hijos de Los Shapis y de The Clash. Propuesta cultural creativa en Lima
}

\author{
Lucie Miramont*
}

* Doctora en Antropología Social e Histórica por la Universidad Toulouse 2 Jean Jaurès (UT2J). Actualmente, es Voluntaria Cívica Internacional en el Instituto Francés de Estudios Andinos (IFEA).

Fecha de recepción: 12/06/2018. Fecha de aceptación: 01/10/2018 


\section{Hijos de Los Shapis y de The Clash. Propuesta cultural creativa en Lima}

\section{RESUMEN}

La escena musical independiente de Lima se caracteriza por ciertas posiciones políticas tanto como acerca de la cuestión de la identidad peruana y el presente artículo propone un panorama crítico de parte de esta escena alternativa ${ }^{1}$. El enfoque es el de un estudio político dentro de lo cual esta escena artística proporciona una puerta de entrada hacia reflexiones más amplias sobre dinámicas sociales. Se presentarán entonces las influencias que tienen estos artistas y cómo, nutriéndose de estas, ofrecen al público una propuesta musical inédita, comprometida e independiente.

Palabras clave: cumbia peruana, punk, política, identidad, música independiente.

\section{Children of The Shapis and The Clash. Creative cultural proposal in Lima}

\section{Abstract}

The independent musical scene of Lima encompasses political issues or refers to the Peruvian identity. This article touches on particular aspects of this alternative scene. From my standpoint, the artistic and political dimensions being very much imbricated, the study naturally leads us to look at the social dynamics at play in Peru. It intends to start from an in-depth analysis of the different influences of the artists in order to understand what inspires them to create and how their inspiration is converted into original and hard-hitting creation songs.

Keywords: Peruvian cumbia, punk, politic, identity, independent music.

1 Este estudio corresponde a una parte de la tesis de doctorado en antropología social que empecé en 2015 y que tiene como título provisorio: Cumbia fusión y gráfica popular en Lima: implicaciones identitarias y recomposiciones sociales en la ciudad de Lima desde la escena alternativa. 


\section{EMPRENDIENDO LAS «RUTAS DEL RECUERDO» ${ }^{2}$ PARA ENTENDER LA «PRODUCCIÓN AUTÓNOMA» ${ }^{3}$ DE UNA MÚSICA ACTUAL ${ }^{4}$}

A inicios de 2015, emprendí una investigación de campo sobre un movimiento musical y artístico particular nacido en la ciudad de Lima ${ }^{5}$. En el marco de la antropología de lo político, estudio las relaciones y mutaciones sociales, económicas y espaciales en un contexto latinoamericano caracterizado por una gran diversidad. Eso es particularmente notable en las grandes ciudades como Lima, marcada por ser un punto importante de confluencia de la circulación de personas, de las ideas y de los bienes culturales. Para tratar de ir más allá de las teorías indigenistas o indianistas, culturalistas y de los estudios sobre la globalización, trabajo sobre un movimiento cultural dentro del cual se cuestiona el vínculo con la identidad en el nivel local. Este proyecto se inscribe así en la reflexión de Marc Abélès, que invitaba a salir de las tesis maniqueas de un imperialismo cultural céntrico —en este caso, norteamericano o europeo-, que se impondría sobre una periferia, aquí, latinoamericana (Abélès, 2008). Se trataría entonces de volver a pensar la teoría de los flujos culturales de Arjun Appadurai (2005) a partir de adaptaciones, interpretaciones, respuestas y prácticas locales condicionadas por la historia, las influencias externas y ciertos hitos y mandatos políticos con respecto a la cuestión de la identidad.

El caso de una escena musical y artística independiente en Lima, que difunde un discurso político particular, fue así revelador de varios procesos de creación musical y cultural a partir de la renovación de una corriente musical local, yendo más allá de una posición de protesta o de resistencia. En el presente artículo utilizaré datos recopilados a partir de entrevistas y observaciones con cuatro bandas que mezclan sonidos y ritmos de cumbia peruana, amazónica y andina, de chicha, de rock, de ska o de punk, citadas por orden de creación: Los Chapillacs (2006, Arequipa) ${ }^{6}$, Barrio Calavera (2006, Lima), La Nueva Invasión (2009, Lima) y Los Truchas (2014,

\footnotetext{
2 Picaflor de los Andes, «Por las rutas del recuerdo», álbum epónimo (1969).

Actitud Frenética, título del compilatorio (1991).

4 Quise, con los títulos de cada parte de este texto, hacer una suerte de "guiño» a las personas con quienes trabajé en mi campo de investigación, citando algunas canciones suyas o de las bandas que le gustan y con las cuales nutrieron sus propias creaciones.

5 El segundo punto de enfoque de mi objeto de estudio es la "gráfica popular» con los siguientes artistas, grafistas y diseñadores (por orden alfabético): Amapolay Manufacturas Autónomas, Brochagorda, Elliot Tupac, Faite, Nidea-Familia Gutiérrez y Ruta Mare. Con las bandas de la escena independiente, forman una red de actores a partir de la cual estudio los intercambios y construcciones de discursos y de ideas, pero también las acciones e iniciativas colectivas que participan de forma crítica y consciente en la construcción del Perú contemporáneo.

6 A pesar de que no es una banda limeña, Los Chapillacs tuvieron un recorrido similar a las otras bandas en sus procesos de creación y de evolución artística en la ciudad de Lima, por compartir circuitos y eventos con ciertas bandas de la movida independiente limeña.
} 
Lima $)^{7}$. Algunas se caracterizan por el compromiso político de la letra de sus canciones, otras participan, aun de forma puntual, de los eventos organizados en el seno de esta escena entre Barranco y el centro de Lima, trabajando así en colaboración y dentro de cierto marco espacial. La cohesión que existe entre estas bandas es, antes de todo, musical, pero se concreta con el compartir de los espacios de conciertos en Barranco y en el centro de Lima. Sin embargo, fuera de estar en la misma programación o de coorganizar algunos eventos, las bandas mantienen entre ellas cierta distancia en cuanto a su evolución y trabajo propio, sin ponerse en una situación de competencia: al contrario, ya que se estimulan entre ellas, según sus integrantes.

He seguido a estas bandas hasta finales de 2017, en sus ensayos y conciertos, compartiendo con sus integrantes discusiones acerca de su formación, aficiones musicales y posiciones políticas. Ubicando su producción cultural fuera de los circuitos oficiales, esta movida que no tiene nombre ni figura de proa funciona de forma independiente y autogestionada, con colectivos que se quedaron en la informalidad hasta hace poco, lo que les daba cierto margen de maniobra y, a la vez, constituía un obstáculo a su desarrollo. Preciso que, en el presente artículo, utilizaré de forma indiferenciada los términos "movida" o "movimiento" para referirme a esta escena, pues este es el vocabulario empleado por los mismos actores.

Para dar una dimensión crítica y reflexiva al panorama musical que hago aquí, voy a tratar de mostrar cómo este movimiento musical independiente propone un producto cultural que se puede considerar como una creación musical activa, en el sentido de que participa, de cierto modo y a partir de un discurso antisistema, de la construcción de una reflexión y de una acción política, por la vía del arte. Formaría entonces parte de un conjunto de cultura activa que, más allá de tener una propuesta nueva y original, invita a los peruanos a tener una visión crítica acerca, entre otras, de las temáticas identitarias y a actuar, creando nuevos modelos, conscientes de la riqueza cultural peruana y abiertos a las influencias. Me concentraré sobre las entrevistas que hice con los integrantes de cuatro de las bandas ${ }^{8}$ y en la cobertura conciertos para alimentar e ilustrar esta reflexión acerca de una creación musical peculiar.

Empezaré por un recorrido en la Lima de las décadas de 1980 y 1990 entre las «barriadas» y el centro, para entender las influencias de los músicos, que condi-

\footnotetext{
Enumeradas por fecha de creación.

8 Los Chapillacs, Barrio Calavera, La Nueva Invasión y Los Truchas que me parecieron, entre otras bandas, ser las que por sus influencias o discursos venían alimentar con ejemplos concretos mi reflexión.

9 Utilizaré el término «barriada» en el sentido que le da Driant cuando remite a los barrios periféricos de Lima, formados a lo largo de la segunda parte del siglo XX: «un espacio que emerge en un proceso de urbanización acelerada», y que se traduce en la ciudad por «importantes mutaciones morfológicas, sociales y culturales» (1991, p. 15).
} 
cionan sus ritmos y sonidos. De allí entraré más en detalle en su proyecto musical independiente, vinculado con preocupaciones acerca de temáticas políticas y de identidad que pueden expresar en sus canciones. Este punto me permitirá tratar más de cerca el tema de la creación, considerando a estos artistas como "creadores» de una nueva propuesta musical, identitaria y política, más allá de artistas «reactivos», posicionándose en contra de una cultura globalizada y de esquemas políticos que no les satisfacen.

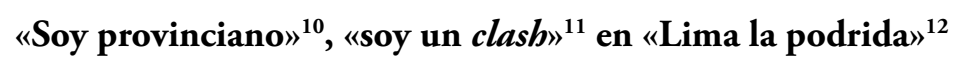

En un contexto de inestabilidad e inseguridad que caracterizaba la Lima ochentera ${ }^{13}$, nacieron dos corrientes musicales que tenían en común el hecho de ser creadas y manejadas por dos grupos de actores marginalizados. Los primeros eran migrantes instalados en los barrios periféricos que, por su procedencia provinciana y sus pocos recursos económicos, fueron despreciados por las clases criollas más altas, padeciendo un racismo que desgraciadamente se puede seguir observando cuarenta años después. Los segundos eran jóvenes de extracción social diversa, que vivían en barrios más céntricos y que se escondían para seguir afirmando sus ideas anarquistas — y a veces nihilistas —, aspirando al derrumbe del sistema capitalista y del poder. Aquí hago referencia, por un lado, a la escena chicha, y por otro, a la escena subterránea, opuestas al nivel musical, pero parecidas en su forma de organizarse: de manera informal y autogestionada ${ }^{14}$. Obligadas a desarrollarse creando sus propios espacios de conciertos y modelos de difusión, estas dos escenas que generaron diferentes estilos musicales fueron las que inspiraron a los artistas de la «movida» independiente y alternativa actual.

\section{«Guitarra chichera»" ${ }^{15}$ con "corazón andino» ${ }^{16}$}

No tengo aquí la pretensión de presentar una historia de la música chicha, trabajo que ya fue realizado por investigadores estos últimos años ${ }^{17}$. Recordaré, sin

10 Chacalón y la Nueva Crema, álbum Éxitos... Éxitos... Éxitos (1978).

11 Psicosis, álbum De aki nadie se salva (2008).

12 Álbum recopilatorio realizado por el Fanzine Tu mamá calata (2005).

13 Con una población que había crecido de forma exponencial sin que se adapten las infraestructuras urbanas, sumado a una crisis económica y a la emergencia de Sendero Luminoso que iba a añadir un conflicto armado a la inestabilidad política y económica que conocía Perú.

14 Desarrollo este paralelo en el artículo "Conciertos autogestionados en Lima, de la chicha y del subte nace la alternativa» (No tan nuevos mundos, 2018).

15 Chacalón y la Nueva Crema, álbum ¡Soy feliz! Nos dice... Chacalón y la Nueva Crema (1986).

16 Los Shapis, título de álbum (1989).

17 La literatura científica abunda en cuanto a este tema; citaré aquí de forma no exhaustiva ciertas referencias, por orden alfabético, como Baylón (2004), Calvo (1997), Espezúa Salmón (2009), 
embargo, algunos datos relativos a esta corriente musical que inspira a jóvenes artistas y músicos contemporáneos.

Como lo mencionaba más arriba, el contexto de creación de este estilo musical es una capital en plena expansión en la cual los migrantes, de origen rural, tienen una vida difícil y precaria, padeciendo el rechazo y del desprecio por parte de las élites criollas y de los limeños tradicionales. Para encontrar fuentes de ingresos y sobrevivir en estas condiciones, estas personas se inventaron empleos, mayormente informales, que eran de servicios o de comercio ambulante, y se organizaron entre ellos para mejorar su vida, trabajando en cooperación para la construcción de viviendas, de infraestructuras y apoyándose para los trámites legales en cuanto al acceso a la propiedad de las tierras que habían «invadido» (Altamirano 1992). El contexto social condicionó así el nacimiento de la chicha:

La «música chicha» puede ser considerada formalmente como un concepto que involucra una sonoridad musical específica, una estética, una coreografía, un tipo determinado de ritualidad e implica un grupo social que la produce, aprecia y consume.

No puede ser considerada como un género musical en sentido estricto, ya que está conformada por diferentes rítmicas y estilos vocales [...] que provienen de otros lugares del planeta y que han llegado al público limeño en un tiempo prolongado y a través de los mass media. (Leyva, 2008)

Los ingredientes musicales reflejaban así la sociedad limeña y eran socialmente marcados, como explica A. Quispe Lázaro: «El huayno ya tenía su audiencia, gente estrictamente migrante andina en los sectores de barrios pobres y algunos de clase media. La cumbia, la guaracha, el son, el mambo, tenían sintonía en sectores de clase media y también populares, el rock, básicamente, en sectores medios» (Quispe, 2009). El resultado musical de este encuentro entre diferentes categorías sociales conoció momentos distintos, pero con una constante de melodía bailable y de temas que reflejaban la realidad de los migrantes.

La década de 1970 estuvo marcada por una dominante "costeña» ${ }^{18} \mathrm{y}$, despreciados por las élites y sin acceso a canales de difusión oficial, los actores de esta

Gargurevich (2002), Huerta-Mercado (2001), Hurtado Suárez (1995), Leyva-Arroyo (2005), Llorens Amico (1983), Quispe Lázaro (2009), Romero (2008), Thierold Llanos (2001) o Velázquez Castro y Vich (2003).

18 Con bandas tales como Los Destellos, el Grupo Celeste o Los Ecos. Con temas y sonoridades más "ahuainadas», la década de 1980 fue la de la chicha «andina», con Los Shapis y Chacalón y la Nueva Crema o Karicia, por ejemplo. Fue en este período que el movimiento alcanzó una audiencia muy importante en los sectores populares, con conciertos masivos que llenaban locales, que no eran salas de concierto sino simplemente donde había espacio, como playas de estacionamiento, estadios, plazas o terrenos desocupados. 
escena crearon sus propios medios de comunicación, como radios propias y una estética llamativa e imperdible para los afiches que proporcionaban los conciertos ${ }^{19}$. En la década de 1980 evolucionaron los temas de las canciones que ya no contaban tanto la difícil vida en la ciudad y el arraigo a la tierra de origen, sino que se trataba de historias de amor, desamor y alcohol. Ritmos alegres y letras con temas «ligeros» y ya no tan sociales alcanzaron un público aún más amplio, con emisiones radiales de chicha o de cumbia peruana que inundaron el conjunto de la ciudad. Al final de esta década, hasta llegaron a firmar el final de la hegemonía cultural criolla, según Thierold Llanos (2001, pp. 187-209).

Entre otras cosas, la elección de Alberto Fujimori en 1990 y la entrada del Perú en su fase de liberalismo económico marcaron un quiebre en el proceso de evolución del movimiento chicha. Este quiebre se volvió aún más palpable con la muerte del cantante Chacalón, «el faraón de la cumbia peruana», en 1994.

Informal y menospreciada, pero masiva y que sigue ritmando las calles de la ciudad, la chicha se situó y se originó en el margen de la cultura oficial y de las élites, como en su momento hizo el huaino en la década de 1950. Lo interesante con la chicha es que es la huella cultural dentro de un momento clave de transformación abrupta de la capital y de todo el país. Corresponde a un momento de auge en las migraciones internas, por el conflicto interno armado, y la crisis económica que creció con el gobierno de Alan García (1985-1990) y el ingreso del país a la dinámica neoliberal que impuso Alberto Fujimori a partir de 1990. Este último marcó giro de las políticas económicas tuvo como efecto un desarrollo exponencial de las actividades informales y de las iniciativas económicas y empresariales privadas, como en el caso del transporte con las "combis». La chicha sería así el sonido de este período clave de oficialización de la informalidad, abrió escenas y espacios en la ciudad, llegando a lo que Hurtado Suárez (1995) llamaba una «insurgencia musical», acercando la chicha al contestatario e irritado mundo «subte» ${ }^{20}$ del centro.

\section{«Ruido para una ciudad muerta»" $»^{21}$ «yo no quiero! $»^{22}$}

En paralelo a la efervescencia de la escena chicha, otra escena también se estaba desarrollando en Lima. Con una audiencia más reducida, pero que gritaba sus ideas

\footnotetext{
19 Hago aquí referencias a los «afiches chicha», que siguen utilizados para anunciar conciertos de cumbia hoy en día, caracterizados por sus colores fosforescentes y su tipología masiva. A la tradicional serigrafía ahora se suman técnicas numéricas de diseño e impresión.

20 «Subte» es el diminutivo de «subterráneo/a» y es una palabra empleada a menudo por las personas con las cuales trabajé en mi investigación de campo para remitir a lo relativo a la escena rock, punk y ska.

21 Eutanasia, Desconcierto, Combustible, Desayunados, Exilio y Anti, parte del título del compilatorio Rock subterráneo!! ii Ruido para una ciudad muerta (agosto de 1989).

${ }^{22}$ Narcosis, álbum Primera dosis (1984).
} 
de contestación y protesta política, la escena subterránea del centro de Lima tenía, al contrario de lo que se podía pensar, mucho en común con la propuesta musical y de organización que se había desarrollado en la periferia de la capital.

Aunque era más elitista, y sobre todo en inglés (León, 2014, p. 28), el rock peruano de la década de 1970, con bandas como Los Saicos, Los Doltons o Los Belkin's, dejó la idea y la voluntad para las bandas de "generar un espacio donde expresarse en español y expresar la realidad local» (Salinas, 2017). Lo que emergió en los años siguientes fue una escena parecida a la del punk inglés de la década de 1970, caracterizada por su discurso de rebeldía, su autogestión y sus arreglos musicales y logísticos con pocos medios y en un contexto de represión. Fabiola Bazo explica así que: «el punk, su actitud y el "hazlo-tú-mismo" tard[aron] casi una década en afianzar en la capital y asumi[eron] su propia identidad en una ciudad que, salvando distancias, compart[ían] con Londres en los setenta: una marcada intolerancia, divisiones de clase, recesión económica y un sangriento conflicto armado» (Bazo, 2017, p. 186). Se trataba, según Marcos Salinas (Fósforo), de un fenómeno social dotado de "una conciencia visceral de la realidad eco-social», y sobre todo "visceralmente contestatario» (Salinas, 2017), en confrontación con todo lo establecido.

En el aspecto político, esta escena se presentaba como anticapitalista, rechazaba cualquier forma de poder absoluto (Greene, 2017, p. 91) y era por esencia básicamente «antisistema» ${ }^{23}$. Más anarquistas o nihilistas con el lema «No hay futuro», los actores de la escena subte padecieron de la censura y de las interdicciones de tocar que a menudo ocurrían ${ }^{24}$.

Los locales más emblemáticos de esta escena autogestionada se ubicaban en su gran mayoría en el centro de Lima ${ }^{25}$. Eran lugares donde se organizaban las tocadas que siempre corrían el riesgo de ser canceladas por la llegada de la Policía y cuya promoción se hacía por la vía de volantes distribuidos en los conciertos. Este tipo de organización, con un «circuito propio»o «minicircuitos actuantes» (Salinas, 2017), trataba de encontrar alternativas para contornar la censura. Pero sin acceso radial, la difusión quedaba en un círculo reducido, sobre todo por la vía de casetes y de los

23 Greene habla al respecto de una «reificación del sistema que hace posible la conceptualización de los procesos estructurales como si fueran totalizantes, dando lugar al fantasma de una entidad externa todopoderosa que es imposible de derrotar salvo que la destruy[an] absolutamente en busca de una renovación purificadora» (2017, p. 32).

24 Fueron varios los músicos encarcelados por ser considerados como partidarios de Sendero Luminoso o del MRTA, muy a menudo de forma equivocada o tomando estas acusaciones como "excusas» para encarcelar a personas que difundían un discurso que llamaba a la revolución.

25 En las Galerías Brasil o el jirón Quilca, por ejemplo. Salinas (2017) cita así El Hueco de Santa Beatriz, la Jato Hardcore y Los Reyes Rojos. 
conciertos, sin llegar a una audiencia importante. En cuanto a los estilos musicales, Fabiola Bazo detalló varios períodos de esta movida:

Hay tres momentos musicales. El período de 1978 a 1983, identificado con hexágonos punteados, con bandas como Anarquía (punk covers), Durazno Sangrando (fusión), Soljani (fusión) y Kola Rock; el período punk, de 1983 a 1986, de las cinco bandas conocidas: Leusemia, Narcosis, Guerrilla Urbana, Zcuela Cerrada y Autopsia (la primera banda hardcore), y el período post-punk, de 1986 en adelante, donde se aprecia una explosión de bandas de distintos géneros y liderado por Voz Propia (dark), G3 (hardcore) y Eutanasia (punk). (2017)

La década de 1990 marcó un cambio determinante en este período de violencia generalizada y de crecimiento importante de la informalidad que iba a transformarse en la norma urbana a lo largo de esta década y de las medidas neoliberales. Parte de esta escena subte se transformó en este período, pasando del underground a algo más mainstream y formalizado ${ }^{26}$, como puede ser el rock peruano actual. Otra parte, más radical, conoció un período de decadencia hasta aparentemente desaparecer, por lo menos la forma que tenía en aquel entonces.

\section{Pero no $«$ se ha muerto mi abuelo» ${ }^{27} \mathbf{y}$ "punks not dead $»^{28}$}

Los dos movimientos musicales ochenteros perdieron su fuerza y se desagregaron en varias corrientes en el trascurso la década de 1990. Entre las diferentes corrientes que nacieron de la chicha, surgió una ramificación especial: la "tecnocumbia», que hasta llegó a alcanzar lo mainstream por su popularidad, con sus artistas femeninas y sus ritmos amazónicos bailables. Aunque haya conocido un éxito fulgurante con cantantes emblemáticas como Rossy War, la tecnocumbia experimentó una caída marcada durante el segundo mandato de Alberto Fujimori: después de haber conocido su auge en el período su reelección (Romero, 2008, p. 9), fue poco a poco burlada y se volvió sinónimo de mal gusto y asociada al fujimorismo ${ }^{29}$.

La década de 1990 también fue testigo de una disgregación de la escena subte que padecía de una mala reputación, asociada a la violencia, a la destrucción y hasta al terrorismo. A esta mala imagen se sumó el impacto en la escena de la crisis

\footnotetext{
26 Con este término, remito al hecho de estar registrados en las instituciones oficiales como Apdayc, Sunat o Indecopi.

27 Juaneco y su Combo, álbum Ven a bailar con Juaneco y su combo (1979).

28 The Exploited, título del álbum (1983).

29 Masiva y popular, la tecnocumbia fue utilizada como medio de propaganda política por Alberto Fujimori, que buscaba su reelección en 2000 con la canción cantada por Ana Kohler, «El ritmo del Chino». Algunos autores explican la caída progresiva del estilo a partir de esta época por haber sido recuperado políticamente, provocando el rechazo de su público, que la consideraban como la música del fujimorismo.
} 
económica y se cerraron locales y salas de ensayos por cuestiones de imposibilidad de inversión (Bazo, 2017, p. 186). Además, padecía de discrepancias internas en cuanto a su ideología ${ }^{30}$ y su evolución: la voluntad de quedarse en la informalidad y de ser independientes para seguir difundiendo su discurso contestatario era incompatible con la voluntad de crecer y alcanzar a un público más amplio, o simplemente mantenerse.

En ambos casos, chicha y subte, las escenas conocieron una transformación por crecer y masificarse o conocer una desagregación. Pero, como sugería el título de esta parte, estas dos corrientes y escenas musicales no murieron y volvieron a surgir en los niveles musical y discursivo en la actual escena independiente.

Si nos enfocamos en lo que podría ser una nueva ola chichera y cumbiera, que resulta ser lo más visible de estos últimos años, vemos que se caracteriza por alcanzar las clases medias altas por la vía de las nuevas generaciones, hoy en día estudiantes o jóvenes trabajadores. Al final de los años 2000 varios acontecimientos concomitantes llevaron la cumbia peruana, como música que se tocaba y se iba a escuchar en vivo, en locales y distritos que no les hubiera abierto sus puertas, fuera de un espíritu de burla de este estilo considerado como kitch y de mal gusto.

El primer hito de este proceso de «subida» hacia sectores sociales altos de la ciudad de estos ritmos populares se puede establecer en 2007, con la desaparición del grupo de cumbia peruana Néctar en un accidente de autobús en Argentina. Según algunos de los músicos y artistas entrevistados, este fue el acontecimiento que hizo que las clases altas se dieran cuenta de que el Perú venía exportando con éxito el género musical que tanto despreciaban. Que este estilo fuera justamente tan bien recibido en Argentina no era un dato menor, porque en América Latina siempre se miró a este país como el más occidentalizado, modelo de tendencias culturales y desarrollo. El mismo esquema de valoración en el extranjero de un producto cultural peruano ocurrió con la salida del álbum compilatorio Roots of Chicha, producido en Nueva York a finales de $2007^{31}$. En cuanto a la producción musical local, se podría considerar como hito la salida del álbum de Bareto ${ }^{32}$, Cumbia, en 2008. Este conjunto de covers de los éxitos de chicha y de cumbia de las décadas de 1980 y

30 Existía entonces un dilema existencial o epistemológico acerca de la orientación que emprendían las bandas, entre quedarse en la informalidad y la autogestión con pocos medios, pero libres, o acercarse a circuitos de producción oficiales y formalizarse. Los que no emprendieron este camino no perduraron mucho: las bandas duraban poco y no se establecieron sellos o productoras en el seno mismo de la escena subte, que hubieran podido perennizarla.

31 Álbum producido por Olivier Conan.

32 Músicos que tocaban reggae en barres de Barranco. La banda conoció un éxito impresionante a partir de este cambio de estilo, hasta volverse hoy en día una de las bandas emblemáticas de la escena musical peruana y se exporta muy bien. 
1990 marcó una cristalización —o por lo menos una afirmación— de este proceso de nueva emergencia musical.

La exposición fotográfica ¡A mi qué chicha!, organizada en el Centro Cultural de España en 2013, vino reforzar la valoración e interés colectivo por la "chicha» como conjunto cultural de música y de gráfica popular. Me parece que el caso de la chicha en el Perú se puede considerar como una expresión peruana o local de tendencias culturales propias de este inicio de siglo XXI, con un aparente retorno o revival de expresiones artísticas antiguas. Efectivamente, en todo el mundo se observa una renovación o valoración de las músicas tradicionales y populares por nuevas generaciones. En Francia, por ejemplo, se pudo observar una recuperación y transformación del tradicional y popular musette y de su acordeón característico por bandas de jóvenes que, a finales de los años 2000, mezclaron este estilo con sus creaciones $^{33}$, renovando parte del estilo llamado chanson française.

En medio de estas renovaciones musicales, lo que caracteriza el movimiento sobre el cual trabajo es su modo de funcionamiento y de organización. Independientes y autogestionados, vamos a ver que la propuesta de estos artistas va más allá de una simple fusión musical.

\section{UN «MEDLEY JUVENIL» ${ }^{34}$ QUE LE PONE «OJITOS HECHICEROS» ${ }^{35}$ A «LA CARACOLA SUBTERRÁNEA» ${ }^{36}$}

\section{Cocktail de «agüita de Manantay» ${ }^{37} \mathbf{y}$ «vitamina inka» ${ }^{38}$, sazón «cumbia 3000» ${ }^{39}$}

Decidí enfocarme sobre estas bandas después de haber iniciado un trabajo prospectivo con sus integrantes y en sus conciertos que, en comparación con otros tipos de eventos, tenían cierta facilidad de acceso y de los cuales era fácil enterarse gracias a las redes sociales. A partir de estos inicios muy empíricos, y a lo largo de las entrevistas realizadas con los músicos, se pudo observar una gran coherencia de las influencias de cada uno, con un patrón de acercamiento tardío a la música popular peruana. La mayoría de las bandas empezaron tocando estilos musicales occidentales, sobre todo rock, a los cuales se agregaron sonoridades de cumbia y de chicha. Terminaron posicionándose, por temas coyunturales y promocionales, como una

\footnotetext{
33 Aquí puedo citar los ejemplos de bandas como Java, Les Hurlements de Léo o les Ogres de Barback, entre otras.

34 Grupo 5, álbum Sueño contigo (1984).

35 Néctar, álbum Los Reyes de la Cumbia (1998).

36 Leuzemia, álbum $A$ la mierda (1995).

37 Juaneco y su Combo, título del álbum (1968).

38 La Nueva Invasión, título del álbum (2016).

39 Los Chapillacs, álbum Odisea Cumbia 3000 (2011).
} 
nueva propuesta cultural, comprometida políticamente. Este acercamiento a estilos musicales locales se acompańó, para la mayoría de los artistas, de una toma de distancia crítica con respecto a lo que estaba «de moda», proceso siempre teñido por la concientización de cierta realidad social, cultural y política peruana.

Entre sus inicios, a lo largo de los años 2000, y sus actividades en el momento de mi investigación, las bandas consiguieron ampliar su público y afianzar a sus seguidores, hasta tener comunidades. Evolucionó así la comunicación y pasaron de la distribución de volantes de promoción de sus conciertos, en el centro de la ciudad o en las universidades, a eventos de Facebook que cuentan ahora con miles de participantes. Afinaron su estilo y afirmaron sus posiciones gracias a discursos políticamente comprometidos. En el aspecto musical, las influencias se volvieron más marcadas a lo largo de los años y se reforzaron los de rasgos de cumbia y chicha tanto como de rock o de punk, influencias que se matizaban en los primeros momentos de un movimiento que no dejó de consolidarse ${ }^{40}$.

Los entrevistados son, así, personas que provienen diversos distritos y clases socioeconómicas, lo que crea grupos heterogéneos, pero con una aceptación y un punto de encuentro común en una movida musical. Se destacó, a lo largo de las entrevistas, una construcción peculiar de su práctica musical colectiva actual, pese a procesos de autodefinición, de interpretación de la realidad y de producción de sentidos distintos. Aunque la extracción socioeconómica haya influido en su formación y su acercamiento a la música, la cuestión de "clase social» en sí nunca fue evocada como un elemento relevante de identificación propia: más bien se pensaban estos rasgos, a menudo distintos en el seno de una misma banda, como elementos que se iban sumando para enriquecer una experiencia colectiva. Observé así una multiplicidad de los discursos y una diversidad de las biografías tomadas como base de la construcción de una práctica colectiva hibrida, tal como un rompecabezas que va sumando piezas diversas para crear una imagen general que, en el caso de las bandas, se visibiliza y se vuelve eficiente en la performance musical y escénica.

El punto en común más importante entre los entrevistados es, entonces, esta primacía de la práctica colectiva, o sea, de la creación musical y cultural, tomada como el resultado de la suma de las individualidades de las experiencias y de los discursos. En el aspecto musical se encuentran así ciertas bases comunes, cualquiera sea el origen socioeconómico. Para cada uno, fue interesante ver que se destacaron

\footnotetext{
40 A inicios de 2018, después del cierre de la investigación de campo, se hicieron más visibles los primeros pasos de un lento proceso de profesionalización de estas personas, cuya gran mayoría, hacia hace poco, tenía otro oficio o actividad que le aseguraba un ingreso económico perenne. Esta última evolución viene de la mano con la formalización progresiva de la movida y de ciertas bandas a inicios de y su pasaje al trabajo con productoras y promotoras oficiales. A la imagen de parte de la escena subte de la década de 1980, decidieron formalizarse para seguir creciendo.
} 
en su infancia y juventud dos vías de contacto con la música, dentro y fuera de la casa de sus padres. Se trató así de lo que considero como una partición entre una cultura musical familiar y el entorno musical urbano: las calles, los mercados, las tiendas, los buses. Aníbal Dávalos, bajista de Barrio Calavera, se acuerda así de su infancia en Pucallpa con la radio de su abuela, en la cual escuchaba folclor, boleros y cumbias de Los Mirlos y de Juaneco y su Combo ${ }^{41}$. Jim Quesada ${ }^{42}$, el guitarrista de los Chapillacs, recuerda haber tenido un contacto con la cumbia fuera de la casa donde creció por lo que difundía la radio continuamente prendida del garaje que estaba cerca de donde vivía. En la misma línea de idea de una música cumbia que estaba presente fuera de sus hogares de los padres, Luis Antonio Vicente, el cantante de la Nueva Invasión, me explicaba: «Mis padres no escuchaban chicha, yo lo escuchaba por el barrio porque sonaba ${ }^{43}$. Sumándose a esta división entre la «música de afuera" y la de "adentro", de la casa que todos parecen haber conocido, viene otro punto común entre estos artistas, cuya gran mayoría son autodidactas: una adolescencia o juventud marcada por el rock, el punk, el ska o el metal. Su afición musical era así girada, antes de todo, hacia a producciones extranjeras y occidentales en su mayoría.

Cada banda creó entonces una mezcla particular, nutrida por las influencias propias de cada uno, pero con esta base «ambiental» cumbiera y chichera y esta afición al rock y al punk $k^{44}$. Entre las influencias citadas por los entrevistados, se encuentran con la misma importancia por un lado bandas como The Clash, los Sex Pistols o los Red Hot Chili Peppers, y por otro, Los Shapis, Juaneco y su Combo o Chacalón. Si me fío de los testimonios de los artistas: en un concierto o en una sala de ensayo siempre llegó un momento en que «salió una cumbia» o "salió una chicha». De allí se hizo la «fusión» o la mezcla, y eso gracias a la gran plasticidad musical y capacidad integrativa que posee la cumbia en su composición. Si resultó difícil entender las motivaciones claras o destacar «decisiones» de hacer este tipo de música, se puede, sin embargo, avanzar algunas explicaciones intrínsecas a este proceso al analizar los discursos de los músicos. Vendría, por un lado, de un contexto cultural favorable con un revival de la chicha en Lima en las clases medias y altas y, por otro, de una suerte de toma de conciencia y de apoderamiento de un tema de identidad cultural. Se dieron cuenta después de la adolescencia y en las universidades, para la mayoría, de que no existía una expresión cultural con la cual se podían identificar. Hijos

41 Entrevista del 20/07/17, Lima, Barranco.

42 Entrevista del 24/07/17, Lima, centro de Lima.

43 Entrevista del 01/10/16, Lima, Barranco.

44 Anibal Dávalos contaba que, en la década de 1990, mientras tenía la oportunidad de conocer a una banda extranjera de rock que venía tocar en Lima, trataba de acercarse al cantante para entregarle un casete de Psicosis y uno de Juaneco y su Combo. 
de una clase media que más y más progresaba, ni cumbia, ni rock, ni blancos, ni cholos, todos comparten una perspectiva crítica acerca del discurso oficial sobre una identidad y una cultura peruana esencialistas y clasistas, pero quedándose fuera de cualquier compromiso o militantismo político partidario.

La cumbia o la chicha que surgió en sus ensayos y en sus creaciones iniciales era una referencia en común, casi inconsciente, algo que formaba parte del cotidiano de todos, de su background, algo familiar, un telón de fondo de infancia y de adolescencia. Unos sonidos que formaban parte de su paisaje y que, de repente, al caer bajo sus uñas o baquetas, cobraba una fuerza y un sentido particular. Pero el camino hasta llenar salas de conciertos en Barranco y en el centro de Lima todavía iba a ser largo desde sus inicios creativos vacilantes y los crepites de su «cumbia de garaje» ${ }^{45}$.

\section{LAS REDES SOCIALES COMO ALTERNATIVAS A «LA RADIO Y LA TELEVISIÓN» ${ }^{46}$}

Como se menciono con respecto a las movidas de las cuales los artistas de la escena independiente son los herederos, la dificultad siempre reside en la difusión de su música y en conquistar a un público, en este caso, con un estilo nuevo, propio e híbrido. Esta característica es algo que tuvo mucho peso en los inicios de las bandas, en una ciudad donde las escenas musicales son tan social como espacialmente marcadas y delimitadas. Tanto Aníbal Dávalos como Luis Vicente me contaron al respecto experiencias similares con los primeros conciertos de Barrio Calavera y de la Nueva Invasión: rechazados por ser demasiado "cumbia» en el caso del público «rockero» y por ser demasiado «rock» en el caso de la gente «cumbiera». De la misma manera, las radios les mantenían las puertas cerradas y, según ellos, esto sucedía tanto por su estilo, que no cabía en ningún molde ni programa musical, como por el matiz político que podía tener su letra ${ }^{47}$.

Sin espacio donde tocar ni radio que las promocione en un período todavía pre Facebook y YouTube, tuvieron que encontrar otras soluciones para difundir su música y darse a conocer. Aprovecharon sus redes estudiantiles y musicales para organizar conciertos en universidades o en locales alquilados, creando sus propias fiestas y escenas que promocionaban distribuyendo volantes en otros eventos. La Nueva Invasión empezó así a afianzar su público en tocadas en las universidades en

\footnotetext{
45 Renato Rodríguez llamaba así con algo de humor la música que tocaban en los inicios, haciendo referencia al garaje rock con sus malas grabaciones y su «feeling un poco oscuro».

46 Psicosis, álbum De aki nadie se salva (2008).

47 Actualmente, bandas reconocidas, y en plena expansión para algunas, a menudo pueden salir en la tele, en programa como Jammin de MovistarPlus, por ejemplo, o en radios como Oasis, para tocadas en vivo y entrevistas.
} 
las cuales estudiaban sus integrantes. Barrio Calavera aprovechó del espacio y de la visibilidad que podían agarrar a partir de los contactos de los integrantes en el seno de la escena rock. A lo largo de los años, ampliaron su espectro escénico y su público creció, en particular gracias a las tocadas en los bares de Barranco que les dieron más visibilidad y, así, audiencia. En su recorrido hacia los line up de grandes festivales ${ }^{48}$, creo que se puede considerar que, además de los conciertos, fue su actividad en las redes sociales, creciente y constante, lo que los llevó hacia cierto reconocimiento.

Gratuito y permitiendo alcanzar a un máximo de gente, Facebook fue la vía de difusión de información privilegiada por la cual apostaron todas las bandas, publicando sus eventos, videos en vivo, fotos y, muy a menudo, agradecimientos a su público. Funciona como una plataforma de relevo de los videos que postean en YouTube y de las fotos que ahora ponen en su Instagram. Ambas redes son también dos vías por las cuales mantienen un contacto eficiente y cotidiano con sus seguidores y aficionados. En varias de las entrevistas, los músicos me contaron su sorpresa, alegría y orgullo al darse cuenta de que, cuando tocaban en provincias, había parte del público que conocía la letra de sus canciones. Me explicaron que eso era el fruto de su actividad en las redes sociales y de la presencia de sus videos en YouTube, que la gente miraba para escuchar y aprender sus letras. Algunos lamentan de vez en cuando la época de antes de la «era de la pantalla», en la cual uno tenía que salir para enterarse de los eventos, mientras ahora no hay tanto contacto e intercambio directo entre la gente. Sin embargo, frente a esta posible pérdida de espontaneidad y de sociabilización concreta y directa, surge el contrapunto de un medio de difusión masivo e instantáneo. Es, por lo tanto, importante tomar los datos relativos al marketing digital y a la visibilidad en las redes sociales con cierta distancia, dado siempre habrá un desfase muy importante entre el número de seguidores de una banda, de vistas en YouTube o de "participantes» en un concierto promocionado por la vía de un evento Facebook y los que realmente asistirán a la performance o comprarán su disco ${ }^{49}$.

\footnotetext{
48 Cabe precisar aquí que las bandas se situaban en fases o procesos distintos mientras se realizó la investigación de campo. Los Truchas, por ejemplo, estaban empezando a tocar en Barranco, mientras en el mismo momento Los Chapillacs tocaban en la explanada del Ministerio de Cultura para la Fiesta de la Música, la Nueva Invasión estaba en el Taytakunan Festival en el Parque de la Exposición y Barrio Calavera se presentaba frente a más 30000 personas en la quinta edición Villa Salva Rock. Estos grandes eventos coexisten en las agendas de las bandas con conciertos en locales más modestos y eventos autoproducidos de alcance mediático menor.

49 Este punto se puede explicar, entre otras cosas, por el cambio en la forma que tiene la gente de consumir y entretenerse con bienes culturales en la era de la desmaterialización y de la conexión a las redes sociales continua. También, en el caso de las bandas, muchos de sus seguidores "participan» de sus eventos en Facebook, cosa que toman como una forma de apoyar a la banda, pero muy a menudo no asisten al concierto (que ahora puede ser transmitido en vivo en Facebook o Instagram), por cues-
} 
Es interesante considerar el éxito que tienen estas bandas ${ }^{50}$ como el resultado de una combinación de factores entre los cuales la comunicación tiene un papel muy importante. La manera de comunicarse de las bandas con su público cuadra totalmente con las costumbres de las nuevas generaciones, que ya no miran mucho la televisión ni escuchan la radio. Las noticias les llegan en su mayoría a través de las redes sociales o periódicos en línea, tanto como la casi totalidad de los intercambios interpersonales que pasan por mensajerías instantáneas, Facebook o Instagram. Pero, obviamente, el medio a partir de lo cual se hace la difusión no basta para conseguir audiencia y no se llena una sala de concierto solamente con likes y notificaciones recibidas en los smartphones. Lo que crea la adhesión del público es claramente la propuesta de estas bandas, lo que expresan y lo que pueden representar. Su público, según las entrevistas hechas en sus conciertos, expresa una cercanía fuerte con las bandas que, para una parte de sus seguidores, llega a ser hasta una fuente de orgullo, ya que consideran a los músicos como sus portavoces. Pertenecen, en cuanto a sus características socioeconómicas, al mismo grupo que su público: una clase media o media alta "alternativa», que tiene o tuvo acceso a estudios superiores, que se define por su discurso progresista y, ante todo, por estar en contra de las derivas y excesos del neoliberalismo, pero quedándose siempre fuera de cualquier militantismo partidario. La performance se hace en «su» ámbito, en los lugares que frecuentan, que no son discotecas de clase alta ni espacios de concierto del Cono Norte, sino bares de Barranco o espacios creados o gestionados puntualmente por las mismas bandas en el centro de Lima ${ }^{51}$.

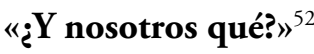

¿Fenómeno de moda superficial o toma de conciencia colectiva más profunda de algo? Si esta podría ser la primera pregunta que uno se plantee frente al éxito de la escena independiente, creo que es mucho más interesante plantear la reflexión en torno a este «algo» que federe a la gente.

Al conversar con gente del público en los conciertos acerca de lo que les atraía de acudir a estos eventos, se destacaron dos tipos de discursos que coexisten en

tión de movilidad y de distancia entre los lugares céntricos de la mayoría de sus conciertos y sus zonas de residencia.

50 Aunque se tiene que considerar que su audiencia y visibilidad quede reducida si tomamos como escala el conjunto de la ciudad de Lima.

51 Se puede mencionar locales como La Noche de Barranco o Sargento Pimienta, que se encuentran en el intermedio entre bar, sala de concierto o discoteca rock. En el centro de Lima, se puede por ejemplo citar el Centro de Convención Festiva o el Palacio del Inca, que fueron lugares utilizados para los conciertos de las bandas.

52 Eutanasia, álbum ¡Sentimiento de agitación! (1990). 
muchos testimonios: la fiesta, y lo que llamaría yo, «la simbólica». En un concierto del centro de Lima, Mauricio ${ }^{53}, 29$ ańos, explicaba: «Me gusta su sonido, su letra, la gana que le ponen a su música. ¡Son alegres!” ${ }^{54}$. Carla, estudiante de 25 años, me contestaba que había salido "de juerga» con sus amigos para bailar y que le divertía la banda que tocaba ${ }^{55}$. Otros, como Katty y Eduardo, estaban más interesados por el discurso de la banda que tocaba, explicándome que se identificaban con la letra y apoyaban las protestas que encontraban en ella: «Esta tarde fuimos a una marcha y estar acá es como apoyar al discurso que tienen ellos, sobre todo en cuanto a la corrupción de los políticos en el país" ${ }^{56}$. En efecto, si lo tomamos desde un enfoque global, estas bandas hablan en sus canciones de las preocupaciones de su generación, en las cuales se mezclan indignaciones, fiestas, política, historias de amor, identidad, borracheras y conciencia de que su misma generación tiene el poder de "cambiar algo".

En el aspecto creativo, más allá de los ritmos y sonoridades de esta música chicha y de la cumbia peruana que fueron el entorno sonoro cotidiano de los artistas, ellos valoran también hoy en día una filiación contestataria con estos movimientos musicales que consideran como una de las primeras formas de oposición peruana a una cultura globalizada. El «sistema» en contra de lo cual se posicionan es un conjunto de varias vertientes, como la corrupción, los abusos cometidos por los políticos, la destrucción del medio ambiente o el racismo, citando aquí solamente temas amplios y generales. Se reivindican anticapitalistas y rechazan una imagen de la identidad que consideran como impuesto por el discurso oficial, una peruanidad que ven como un producto fácilmente exportable y consumible. Varios definieron el mismo concepto de peruanidad como un marco impuesto, algo fácil de valorar para que la gente se siente orgullosa del hecho de «ser peruano», haciendo olvidar los problemas políticos, sociales y ambientales que conoce el país. En sus canciones, en sus discursos, llaman justamente a una toma de conciencia de la capacidad de acción de cada uno, convencidos de que nos definimos por nuestros actos. Su posición muy marcada en cuanto a la cuestión identitaria me llevó a reflexionar de nuevo acerca de cómo yo pensaba la «identidad» en mi trabajo de doctorado en antropología. Mientras algunos me provocaban devolviéndome la pregunta con un: «Y para ti, ¿qué es la identidad francesa? ¿Qué es ser francés?», otros rechazaban el tema de la definición de la peruanidad por considerarlo como una manipulación.

\footnotetext{
53 Por cuestiones de respeto del anonimato de las personas entrevistadas, los nombres han sido cambiados.

54 Concierto en el centro de Lima, 16/11/16.

55 Concierto en Barranco, 29/07/17.

56 Concierto en el centro de Lima, 26/11/16.
} 
Me di cuenta de que, a través de las preguntas que les hacía en cuanto a su autodefinición, los estaba obligando a situarse en un marco definitorio y a categorizarse, cosa que siempre me había negado en hacer en el plano personal y que me hubiera resultado extremadamente complejo. Estaba, con esta pregunta, simplemente repitiendo un esquema europeocentrista, considerando la «otredad» de las personas con quienes trabajaba como lo que les definía y quedándome, en cierta medida, en su «exotización». Había entonces que cambiar un poco la focal...

Hartos, como el público que conquistaron, de ser «objetos» de una definición esencialista, de la misma manera que pudieron estar hartos de ser «sujetos» de investigación, cifras sociológicas y peruanos definidos por su apellido, ciudad de origen de sus padres, su universidad o su distrito de residencia, quieren actuar y aprovechar del margen en el cual sitúan su música, entre estilos, escenas e informalidad para desarrollar su propuesta.

\section{«DEL BARRIO PA' LA ESCENA» ${ }^{57}$ : PERFORMANCE Y AUTOGESTIÓN}

\section{"Camina bonito»" pero "hazlo tú mismo»"}

La producción independiente y la autoorganización permitieron a estas bandas generarse un espacio donde tocar, lo que Marcos Salinas consideraba como una «herencia del ideario rock» (2017) que, como lo vimos, es parecido en cuanto a su modo de funcionamiento a una parte de lo que se podría considerar como un «ideario chicha». La autogestión tiene que ser, en el caso de la escena independiente, mirada a la luz del contexto cultural peruano en el cual es difícil emerger para músicos locales, dado el peso de la globalización cultural y de su impacto en las industrias locales y en los gustos del público. Camilo Riberos, hablando de bandas de ska limeñas en la segunda parte de la década de 2000, consideraba esta organización como una respuesta o más bien una construcción condicionada por el contexto actual (Riberos, 2012, p. 366). Más allá de una manera de organizarse y de trabajar de forma horizontal bajo sus propias reglas, la autogestión puede también ser considerada como una herramienta o un argumento político para criticar el sistema capitalista y posicionarse en una dinámica distinta de forma colectiva. Fernando Castro, tecladista de la Nueva Invasión, analizaba la autogestión en el campo de la música y de la

\footnotetext{
57 La Inédita, álbum Chichamuffin (2012).

58 La Nueva Invasión, álbum Súbele a la radio (2011).

59 Traducción castellana del lema "Do it yourself», que en sí constituía parte de la filosofía punk de la década de 1970 en Inglaterra y de todos los movimientos punk en general. Remitía, en este caso, a la idea de salir del consumismo, autogenerándose los medios, entre otros, de producción musical y de difusión.
} 
producción artística en general de la forma siguiente: «Somos conscientes de que queremos algún cambio, algo nuevo dentro de este sistema porque para salir de este sistema no lo vamos a hacer solos. Creo que, más bien, el neoliberalismo nos lleva al individualismo, pero justamente hay que armar comunidad ${ }^{60}$.

Como se mencionó líneas arriba, lo primero que tuvieron que hacer los actores de la escena independiente fue encontrar un espacio de expresión musical. En el contexto del final de los años 2000, la escena de Barranco era difícil de acceso, con una propuesta musical más cercana al entretenimiento de masa y con poco margen de maniobra para bandas jóvenes. Por otro lado, estaba el centro de Lima, donde decidieron invertir su energía. Espacio de diversidad cultural y social, zona comercial y de tránsito, el centro es considerado por varios como un lugar de cruce, encuentros y posibilidades de expresión cultural. En este marco espacial, los actores tuvieron que crear sus propios espacios de conciertos dentro de bares, locales asociativos o universidades. Construían así su propia plataforma puntual de difusión musical puntual, hasta efímera, pero libre de cualquier marco oficial o presión exterior para cumplir con una supuesta espera musical. La dificultad para conseguir espacios confirió tal vez a esta escena un carácter huidizo, en movimiento y acción constante, buscando dónde tocar. Aníbal cuenta así que los inicios de la escena independiente eran parecidos a los tiempos del período subte que conoció: «Eran espacios que de un momento a otro se tomaban, se abrían. ¿Un bar acá? Se tocaba acá. ¿Una casa? ¿Un local comunal? Se tocaba en una casa o en un local comunal. No había un local fijo, un espacio definido» ${ }^{61}$.

Desde un punto de vista más analítico, la ciudad de Lima es un terreno fértil para las acciones e iniciativas colectivas, en particular musicales. Sus fronteras socioespaciales tienen que estar pensadas como implicando un franqueamiento de sus límites. Eso se volvió posible gracias a la multipertenencia, a la pluralidad de sus habitantes cuya parte se niega, como los artistas de la escena independiente, a enmarcarse en una categoría social o identitaria. Se adaptan a las situaciones y desplazan sus escenarios, situándolos, por este carácter mudable, en los espacios que ellos mismos hacen surgir entre las diferentes «zonas» de la ciudad. Creando lugares temporarios de expresión musical, están tratando indirectamente de proponer una alternativa a una «espacialización» urbana muy fuerte, siempre con la meta de ampliar su aura discursiva, preocupados por su audiencia y visibilidad.

Con una posición rebelde y antisistema, y por la creación de una nueva música y escena, van más allá de lo que podría ser una resistencia frente a un sistema. Son

60 Entrevista del 11/10/16, Lima, Barranco.

61 Entrevista del 20/07/17, Lima, Breña. 
constructores y creadores de una nueva propuesta artística que se concreta en sus performances y en la conciencia de que sus actos creativos tienen un alcance político.

\section{Los nietos de «la pastorcita» ${ }^{62}$ «bailando ska» ${ }^{63}$}

Cuando empecé a trabajar sobre los conciertos, me pareció interesante reflexionar dentro del marco de lo que el antropólogo Michel Agier llama la "perspectiva situacional» (1999, p. 14), que permite pensar las performances musicales en su globalidad de forma dinámica. Siguiendo esta metodología, tomé así en consideración dos tipos de información para cada evento: la «situación» y el setting (Agiar, 1999). En este trabajo, la "situación» remite así al concierto en concreto ${ }^{64}$ y lo que representa este evento ${ }^{65}$. La "situación» se vincula de forma estrecha con el setting, que la condiciona siendo conjunto de coacciones o presiones que influyen en su construcción. Los artistas actúan, de forma consciente o no, para invertir el vínculo entre las «situaciones» y el setting, o sea para que el evento impacte de una forma $\mathrm{u}$ otra, sobre el contexto, según la situación social y política. Pueden así crear eventos y darles un sentido peculiar con esta meta de un cambio político y social profundo o, en una escala menor, deshacerse de una presión u obligación discursiva oficial organizándose de forma autogestionada. Los conciertos tienen entonces que ser considerados como "performances», siendo el resultado de actos creativos y del sentido que se les da:

Las representaciones [...] tienen que ser entendidas literalmente, es decir como un sentido simbolizado dentro de producciones que se muestran, tomando así el carácter de performances. Con la palabra performance, me refiero a la ejecución de obras artísticas o rituales, resultando de una concepción de la obra que se espera y que en sí es el objeto de una comunicación con el público (Agier, 1999, p. 135, traducción de la autora).

Estas performances tienen una capacidad unificadora y creadora de colectivos, justamente a partir del momento en que se establece, por un lado, el vínculo con el público con quien se comunican los artistas por la vía de su música, y por otro, entre los mismos artistas que actúan, creando estas performances dentro del mismo marco y contexto cultural y político. De esta forma se crea una comunidad de actores-creadores que ocupan y transforman, de forma puntual pero repetida, algo de la ciudad y de las conexiones sociales que existen en ella.

\footnotetext{
62 Los Destellos, álbum Destellantes (1974).

63 Barrio Calavera, álbum Suena calle (2009).

${ }^{64}$ Lo que se va a tocar, el número de entradas, los precios, la escenificación, etc.

65 Lo que representa para la gente, que sea una fiesta para divertirse o una manifestación política en el sentido amplio, por ejemplo.
} 
Desplazándose por la ciudad para ir a cantar, bailar o solamente estar presente y escuchar una música particular, se puede considerar a estos actores, músicos y público como la prueba de la elaboración de un colectivo unido alrededor de una propuesta cultural común. La música que se comparte en el seno de este conjunto o red ya lleva en sí una carga política ${ }^{66}$ y social fuerte, por el quiebre que representa al fusionar estilos distintos con una conciencia simbólica de lo que representaron en la historia cultural peruana ${ }^{67}$.

Se podría fácilmente considerar a esa comunidad como «rebelde» o que se posicione en resistencia o desafío frente a una realidad social y política y, sobre todo, frente a un discurso oficial sobre esta realidad. Sus creaciones musicales - y, por extensión, sus performances - serían como una puesta en la luz o revelación pública de lo que James Scott llamaba la «infrapolítica de los dominados» (Scott, 2009). La creación musical y su difusión podrían entonces considerarse como el paso de una resistencia que Scott llamaba «discreta»: la visibilización de esta resistencia y, en este caso, su puesta en escena. Me parece, sin embargo, que, si se consideran las acciones de estos actores solo dentro el marco de una «resistencia» frente a una presión exterior, se les sigue considerando dentro del marco de una relación de dominación (con las instancias oficiales y órganos institucionales) que condiciona su propuesta. Es importante ir más allá de esta perspectiva acerca de su posición y acciones que se definirían como «en contra» de algo por esencia, y pensarlas como creaciones originales.

\section{ACTIVOS MÁs QUE REACTIVOS, «Y QUE SIGAN TOCANDO» ${ }^{68}$}

Trabajar sobre la creación cultural permite atrapar un instante de interacción y de acción, un «aquí y ahora» particular en lo cual se cristalizan varias implicaciones políticas y sociales acerca de la construcción de un ideario nacional. La movida musical independiente limeńa, afirmada y respaldada por una parte visual con los artistas que hacen gráfica popular, me confiere una entrada, desde su centro, en una red en la cual trabajo sobre las evoluciones sociales a partir de lo que es una cultura activa, en reinvención, relocalización o resituación constante. Este carácter le confiere su fuerza para situarse en los márgenes de lo oficial, en las «zonas de contacto» (Pratt, 2010) entre diferentes ámbitos, sean musicales o sociales.

Reivindicar la creación de una propuesta cultural nueva e independiente que se desarrolla en un espacio — este también creado de forma independiente- permite

\footnotetext{
66 Fuera de cualquier ideología partidaria.

67 Aquí no se hace referencia a una historia oficial, sino a una historia vivida e integrada de forma personal por la gente, pero cuyas experiencias, por su semejanza, construyen su propia memoria y versión de los hechos pasados, compartidas colectivamente.

68 Los Truchas, álbum Chicha en asteroides (2015).
} 
entonces a estos artistas tomar una posición que se distingue de una resistencia en contra de una ideología política, económica y social. Por este tema prefiero considerar a estos actores como creativos, más que reactivos, dado que están difundiendo, entre otras cosas, nuevas formas de pensar la identidad peruana. Sin embargo, queda por exponer y entender ciertas paradojas, desfases o negociaciones entre los discursos de las bandas, antisistema o antiglobalización, y las prácticas que se podrían considerar como "prosistema", como, por ejemplo, el hecho de tocar en Barranco para un público de clase media y media alta. Esta ambivalencia nos podría recordar aquí las paradojas que contienen las manifestaciones de la modernidad que había empezado a evidenciar Max Weber a inicios del siglo XX. Este sería el caso de bandas que quieren crecer para poder vivir de su arte, y esta profesionalización implicaría tanto una oficialización de su estatus como entrar en un mercado musical regido por las industrias culturales.

Solucionar esta contradicción entre discurso y práctica o deseos implicaría que consiguiesen concretar un modelo de difusión lucrativo, pero no capitalista; internacional, pero no global. El primer paso hacia una forma de «equilibrio» entre los discursos y las prácticas se puede, por ejemplo, observar con los artistas de gráfica popular con quienes trabajo, que reivindican su estatus de profesionales creadores de un producto con un precio, porque el diseño y la gráfica es su trabajo. La valoración laboral justa de una actividad artística y el reconocimiento de los artistas como profesionales que trabajan podría ser una pista para explorar en el estudio de los elementos en favor de la reducción de la paradoja mencionada.

Este punto paradójico no quita interés a este ejemplo local de organización y creación cultural. Al contrario, me parece que se encontrar un eco más amplio si se toma esta propuesta como un modelo "alternativo» que intenta y se esfuerza en posicionarse en paralelo a un modelo "globalizado", que está encarnado por lo que promueve, difunde y hasta impone lo «oficial». Eso viene a alimentar una forma de pensar América Latina como un lugar donde se estaría tratando de crear y asumir, poco a poco y dentro de un contexto globalizado y marcado por el liberalismo y el capitalismo, identidades y políticas propias, con modelos creados en el ámbito local. Existen así iniciativas que quieren expresar y plasmar en sus expresiones la realidad social actual y sus particularismos, saliendo de la herencia pesada de un continente que fue construido como un espejo de Europa. Permite así ver más allá de las teorías de un imperialismo cultural opaco y aniquilador de propuestas locales, que en realidad son numerosas y están cobrando importancia, algunas nacidas así entre un vinilo de Los Shapis y de The Clash. 


\section{REFERENCIAS BIBLIOGRÁFICAS}

Abélès, M. (2008). Anthropologie de la globalisation. Paris: Payot et Rivages.

Agier, M. (1999). Linvention de la ville - Banlieues, townships, invasions et favelas. Paris: Éditions des Archives Contemporaines.

Altamirano, T. (1992). Migración y estrategias de supervivencia de origen rural entre los campesinos de la ciudad. En E. Kingman Garces (ed.), Ciudades de los Andes: homogeneización y diversidad (pp. 389-425). Lima: IFEA.

Appadurai, A. (2005). Après le colonialisme: les conséquences culturelles de la mondialisation. Paris: Karthala.

Bailón, J. (2004). La chicha no muere ni se destruye, solo se transforma. Iconos: revista de Ciencias Sociales, 18, 53-62.

Bazo, F. (2017). Desborde subterráneo, 1983-1992. Lima: Museo de Arte Contemporáneo de Lima - 33 RPM.

Calvo, R. (1997). Música andina urbana: el caso de la chicha en el Perú. Revista Folklore Americano, 58, 123-128.

Espezúa, D. (2009). ¿Cultura chicha? Crónicas urbanas: análisis y perspectivas urbano regionales, 13(14), 99-110.

Driant, J.-C. (1991). Las barriadas de Lima: historia e interpretación. Lima: IFEA.

Gargurevich, J. (2002). La comunicación imposible. Información y comunicación en el Perú del siglo XVI. Lima: UNMSM - Fondo Editorial.

Greene, S. (2017). Pank y revolución - 7 interpretaciones de la realidad subterránea. Traducción: Julio Durán. Lima: Pesopluma.

Huerta-Mercado, A. (2001). jAl fondo hay sitio! Un panorama de la cultura urbana limeña. Lima.

Hurtado Suárez, W. (1995). Chicha peruana, música de los nuevos migrantes. Lima: Grupo de Investigaciones Económicas.

León, F. (2014). Salamanca Sixties, un estudio sobre el rock en la clase media de Lima. Lima: Andina.

Leyva, C. (2005). Música "chicha", mito e identidad popular. El cantante peruano Chacalón. Quito: Universidad Andina Simón Bolívar, 62,

Leyva Arroyo, C. (2008). Chacalón, la música chicha y sus intérpretes. En Rommel Plasencia (ed.), Otras miradas, géneros al margen de la cultura de hoy. Lima: UNMSM.

Lloréns, J. (1983). Música popular en Lima: criollos y andinos. Lima: Instituto de Estudios Peruanos.

Pratt, M. L. (2010). Ojos imperiales, literatura de viajes y transculturación. México, D. F.: Fondo de Cultura Económica.

Quispe, A. (2009). Música chicha: lo nuevo de fines de la primera década del siglo XXI. Revista Construyendo Nuestra Interculturalidad, 5(4), 1-4.

Riberos, C. (2012). Las formas de organización de las escenas musicales alternativas en Lima. El caso de las bandas de ska en el bar de Barnabé del 2005 al 2007. Tesis de licenciatura de Antropología, Lima: PUCP, Facultad de Ciencias Sociales. 
Romero, R. (2008). Andinos y tropicales: la cumbia peruana en la ciudad global. Lima: Pontificia Universidad Católica del Perú.

Salinas, Marcos (2017). Subterráneos. Historias, vigencias o nostalgias. Publicado en línea en la página Laberintos Urbanos. Recuperado de https://laberintosuburbanos. wordpress.com (02/09/2017)

Scott, James C. (2009). La domination et les arts de la résistance. Fragments du discours subaltern. París: Éditions Amsterdam.

Thierold Llanos, Jorge (2001). La chicha, como un nuevo y desconcertante nosotros. Debates en Sociología, 25-26, 187-211.

Vich, V. (2003). "Borrachos de amor": las luchas por la ciudadania en el cancionero popular peruano. JCAS Occasional Paper, 15, 2-22 